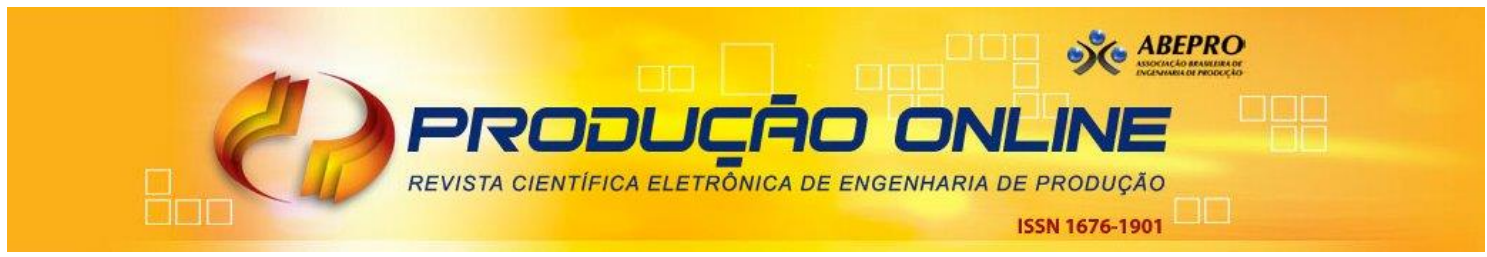

\title{
PROPOSIÇÃO DE UM MODELO DE GESTÃO PARA MICRO E PEQUENAS MARCENARIAS DO SETOR MOVELEIRO
}

\section{PROPOSAL FOR A MANAGEMENT MODEL FOR MICRO AND SMALL MARCENARIES IN THE MOBILE SECTOR}

\author{
Guilherme Wollmann da Costa* E-mail: guiwollmann@gmail.com \\ Bárbara Pisoni Bender Andrade* E-mail: barbarabender1997@gmail.com \\ Fabio Antonio Sartori Piran* E-mail: fabiosartoripiran@gmail.com \\ *Instituto de Ciências Exatas e Tecnológicas (ICET), Universidade Feevale, Novo Hamburgo,
} RS

\begin{abstract}
Resumo: O objetivo deste artigo é propor um novo modelo de gestão focado especificamente em micro e pequenas marcenarias do setor moveleiro. Para cumprir este objetivo foi utilizado o método de pesquisa da Design Science Research (DSR) na elaboração de um artefato prático que consiga equalizar as dificuldades de subsistência encontradas no segmento e atender às necessidades específicas não contempladas por modelos de gestão genéricos. Além disso, o estudo criado foi amparado na pesquisa bibliográfica de dois marcos teóricos: "Modelos de Gestão" e "Setor moveleiro e suas características" e na análise comparativa de três modelos de gestão selecionados: "Seis Caixas", "McKinsey 7s" e "Estrela de Galbraith". O modelo desenvolvido foi chamado de Marcenaria 5A e é composto pela segmentação da empresa em 5 setores: Administrativo, Comercial, PCP, Produção e Execução. O artefato apresenta também os macros processos presentes em cada um dos setores bem como suas relações e fluxos de trabalho e informação.
\end{abstract}

Palavras-chave: Modelo de gestão. Marcenaria. Setor moveleiro. MPE. Setores. Processos.

Abstract: The aim of this work is to propose a new management template specifically designed for micro and small wood workshop of furniture sector. For this, the Design Science Research was used in the elaboration of a practical artifact in order to equalize the subsistence difficulties observed in the segment and comply with the specific requirements that haven't been contemplated by generic management models. Moreover, this study was supported by two theoretical frameworks: "Management Model" and "Furniture Industry and its Characteristics" and the comparative analysis of three selected management models: "Six Box", "McKinsey 7s" and "Star Model by Galbraith". The developed model was called Marcenaria 5A and consist of business segmentation in 5 Areas: Administrative, Commercial, PCP, production and execution. The artifact also presents the macro processes present in each of the sectors as well as their relationships and workflows and information.

Keywords: Management model. Joinery. Furniture sector. MPE. Sectors. Processes.

\section{INTRODUÇÃO}

No Brasil, existem diversos critérios para a classificação do porte das empresas. Dentre eles, o principal é elaborado a partir da Lei do Simples Nacional ${ }^{1}$ (BRASIL, 2016) onde se caracteriza como microempresa (ME) aquelas que 
apresentarem uma receita anual bruta de até $R \$ 360$ mil e empresa de pequeno porte (EPP) as que apresentem de $R \$ 360$ mil a $R \$ 3,6$ milhões. Formando assim o conceito de Micro e Pequena Empresa (MPE).

As empresas deste porte tiveram participação superior a $97 \%$ em quatro setores de atividade (Indústria, Construção, Comércio e Serviços) em 2015. Em contraponto, são as que apresentam o índice mais baixo de taxa de sobrevivência nos mesmos setores (GUIMARÃES; CARVALHO; PAIXÃO, 2018). Quando analisados separadamente, cada setor apresenta empresas que se encaixam em mais de um setor de atividade, como é o caso das moveleiras que atuam frequentemente como Indústria e Comércio.

A indústria moveleira pode ser segmentada sob diferentes critérios, como por exemplo (FEREIRA et al., 2008): (1) Tipo de matéria prima utilizada; (2) uso ao qual o móvel se destina; (3) forma organizacional adotada no processo produtivo; e (4) design utilizado. Além disso, em cada um destes segmentos existem inúmeros subgrupos. O processo produtivo, por exemplo, assume distintos sistemas de organização quando se trata de fabricação de móveis planejados, móveis seriados ou móveis sob medida (GALINARI et al., 2013). Para a última modalidade se confere a condição de "marcenaria" (LEÃO, 2010).

A atividade das marcenarias é registrada em praticamente todo o território nacional (GALINARI et al., 2013) e é realizada, na maioria das vezes, por pequenas empresas que criam móveis customizados de acordo com a necessidade e desejo de seu consumidor. Grande parte dos marceneiros aprendeu a profissão com a família (FUJITA et al., 2015) e, a partir disso, organizou uma estrutura empresarial com controle e gestão familiar (GORINI, 1998). Essas medidas trouxeram para esta cadeia um paradigma de "descontinuidade empresarial" (SANTOS et al., 1999), pois induzem uma dificuldade para a implementação de inovações sob âmbitos administrativos/gerenciais e modernizações (GALINARI et al., 2013).

Apesar da dificuldade de implementação neste setor do mercado, existem diversos modelos de gestão amplamente difundidos e pesquisados. Entre eles, destacam-se três: Modelo Seis Caixas (WEISBORD, 1976), Modelo McKinsey $7 S$ (WATERMAN, PETERS, PHILLIPS, 1980) e Modelo Estrela de Gal-braith (GALBRAITH, 2012). Os trabalhos citados contribuem para implementação de um modelo de gestão em uma micro ou pequena empresa. No entanto, os modelos 
desenvolvidos são, em geral, genéricos e buscam contemplar uma ampla gama de empresas e negócios. Contudo, entende-se que um modelo de gestão desenvolvido especificamente para micro e pequenas marcenarias pode ser uma contribuição para essas empresas, por atender características setoriais específicas não consideradas em um modelo genérico.

Com base neste contexto, o objetivo deste artigo é elaborar um modelo de gestão para as micro e pequenas marcenarias do setor moveleiro. Com isso, sob os conceitos do Manual de Oslo (OCDE/2005), entende-se que esse artefato é uma contribuição de inovação não tecnológica para o setor, por se tratar de uma inovação organizacional e gerencial.

Tal modelo apresentará as áreas internas presentes em uma MPE do setor moveleiro atribuindo a cada uma seus devidos processos e suas atribuições frente à estratégia da empresa. Ainda, pretende propor como devem ser as relações de diálogos a serem cultivados no ambiente interno da organização e uma relação de divisão de tarefas e atribuições em prol do desenvolvimento pessoal de cada colaborador da equipe.

Este estudo apresenta além desta introdução, uma revisão bibliográfica dos marcos teóricos: "modelos de gestão" e "setor moveleiro e suas caraterísticas". Passando por um aprofundamento teórico sobre três modelos selecionados (Seis Caixas, McKinsey 7s e Estrela de Galbraith) e uma análise comparativa entre os mesmos. Em seguida trás uma descrição das etapas metodológicas utilizadas. Ao fim, trás a apresentação e discussão dos resultados obtidos bem como a ilustração do artefato desenvolvido e encerra com as referências utilizadas na construção desta produção.

\section{REFERENCIAL TEÓRICO}

\subsection{Modelos de Gestão}

A eficácia que provém da existência de um modelo de gestão bem definido dentro das organizações faz com que este seja um tema amplamente debatido e estudado. Desta forma, existem distintos modelos de gestão, como por exemplo: Modelo Burke Litwin (BURKE, LITWIN, 1992), Modelo Fractal Web (MCMILLAN, 
2002), Modelo Five Track (KILMANN, 1986), Modelo Seis Caixas (WEISBORD, 1976), Modelo McKinsey 7S (WATERMAN, PETERS, PHILLIPS, 1980) e Modelo Estrela de Gal-braith (GALBRAITH, 2012).

Após a pesquisa destes modelos de gestão com base em periódicos científicos, foi realizada uma análise interpretativa de cada um, com o intuito de selecionar três deles para uma análise aprofundada. Após, determinou-se que os modelos Seis Caixas (WEISBORD, 1976), McKinsey 7S (WATERMAN, PETERS, PHILLIPS, 1980) e Estrela de Gal-braith (GALBRAITH, 2012) seriam os selecionados devido à abrangência teórica e da boa modelagem ilustrativa encontrada para cada um, o que foi considerado um facilitador para a implementação dos modelos na indústria tanto pelo caráter didático quanto pelo teórico/prático. Para oferecer uma visão mais aprofundada de alguns destes modelos, os mesmos são descritos a seguir.

\subsubsection{Modelo Seis Caixas}

Desenvolvido por Marvin Weisbord (1976) o modelo Seis Caixas foi inicialmente concebido para que instituições de ensino pudessem realizar um diagnóstico organizacional. Segundo Verghese (2007) este modelo fornece uma importante ferramenta de atuação para identificar forças, oportunidades e áreas problemáticas de uma organização. São categorizadas seis áreas (caixas) de análise para a realização do diagnóstico organizacional: finalidade, estrutura, relacionamentos, recompensas, liderança e mecanismos úteis (HAMID et al., 2011).

Finalidade é o propósito, são os objetivos e metas da organização que devem ser seguidos por todos os membros da equipe (VERGHESE, 2007). Estrutura é a imagem real da escala de poder e relações da organização (HAMID, et al., 2011). Relacionamentos são as trocas interpessoais e tudo que as cercam. (HAMID, et al., 2011). É preciso destacar as avaliações referentes aos conflitos existentes: ainda que os mesmos sejam inevitáveis, a forma com que são geridos afeta diretamente os seus reflexos, os quais podem ser positivos ou negativos (VERGHESE, 2007).

A caixa "Recompensas", segundo Verghese (2007), trata da elaboração de um sistema de recompensas que contemple desde como as pessoas se sentem motivadas até como o sistema lhes recompensa pelo cumprimento das metas institucionais. O item "Liderança" é onde se encontram os líderes setoriais da empresa 
e, tudo aquilo que ele utiliza para exercer suas atribuições (HAMID, et al., 2011), o que inclui: gerenciamento de conflitos, estilo de liderança, identificação de propósitos, entre outros (VERGHESE 2007). E por fim, os mecanismos úteis são os métodos que ajudam as equipes e os líderes a realizar e coordenar suas atividades (HAMID, et al., 2011).

Os seis pilares definidos por este modelo de gestão podem ser identificados e analisados na Figura 01. A ilustração foi desenvolvida por Annie Verghese em "OD Interventions for Sustainable Excellence in Higher Education".

Figura 01 - Modelo Seis Caixas

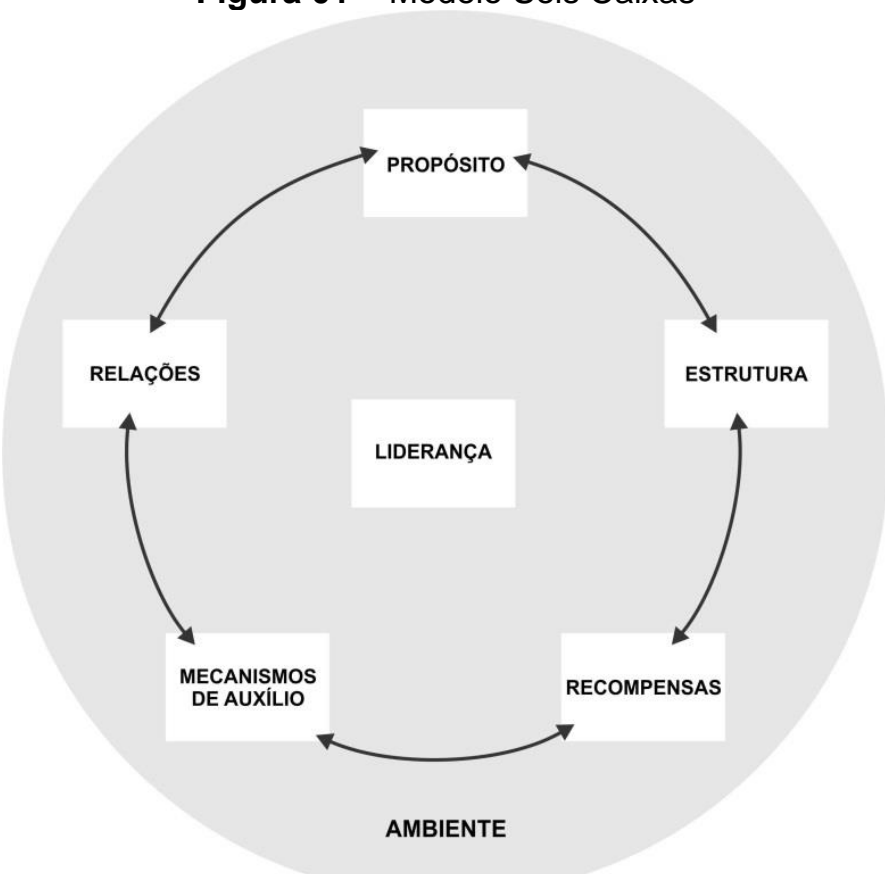

Fonte: Adaptado de Verghese (2007)

\subsubsection{Modelo Mckinsey 7S}

Este modelo de gestão foi desenvolvido em 1980 por Thomas J. Peters e Robert $\mathrm{H}$. Waterman Jr. em face à carência por definições coesas e úteis de organizações (CHEAL, 2008). Ele parte da categorização de uma organização sobre 7 eixos, que são: Estratégia, Estrutura, Sistema, Habilidades, Funcionários, Estilo e Valores Compartilhados (DUTRA, 2005).

Segundo Ravanfar (2015) as categorias podem ser objetivamente descritas sendo: Estratégia o plano da empresa para obter vantagem competitiva e se sustentar no mercado; Estrutura: o organograma de cargos da empresa; Sistema: os processos 
e procedimentos internos; Habilidades: as capacidades e competência dos colaboradores; Funcionários: os mecanismos de recrutamento, seleção e treinamento dos colaboradores; Estilo: o tipo de liderança utilizado pelos superiores e por fim; Valores Compartilhados: são as diretrizes de comportamento de toda a organização.

Dentro dessas categorias, os autores ainda as classificaram como "hard" (Estrutura, estratégia, funcionários, e sistemas) e "soft" (habilidades, valores e estilo) onde os itens do primeiro grupo são facilmente detectáveis e documentáveis e os do segundo grupo, por serem diretamente ligados às pessoas, são mais difíceis de mensurar e influenciar (DUTRA, 2005). Os sete eixos e a classificação dos mesmos podem ser mais bem compreendidos a partir da análise da ilustração na Figura 02 abaixo.

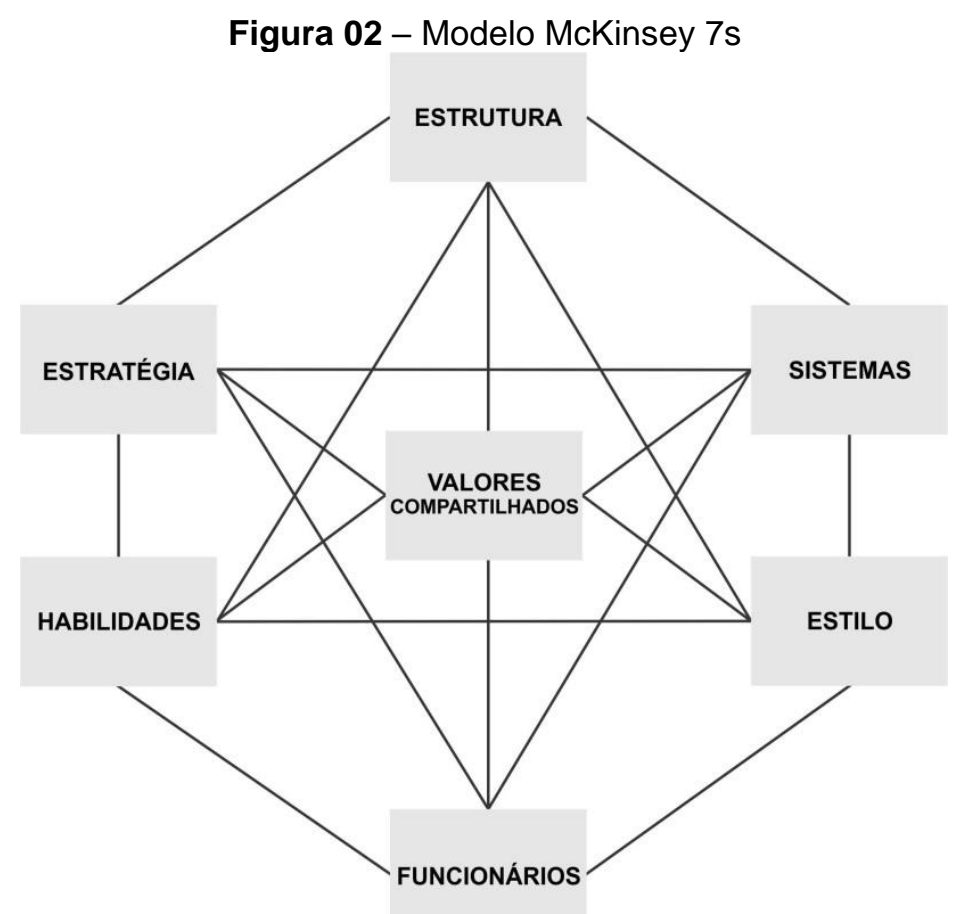

Fonte: adaptado de Cheal (2008)

\subsubsection{Modelo Estrela de Galbraith}

Este modelo de gestão carrega este nome por tratar da organização do seu método sob cinco aspectos relacionados entre si. São eles: Estratégia, Estrutura, Processos, Recompensa e Pessoas (GALBRAITH, 2012). Segundo Galbraith (2012) a atribuição de cada ponta é a seguinte: Estratégia é a orientação principal da empresa; Estrutura apresentará a definição dos poderes; Processos trarão a 
capacitação necessária para o desempenho das funções; Recompensa é o que irá engajar as atividades e Pessoas são a determinação de quem participa do processo. A Figura 03 reproduz o fluxo das informações e atribuições segundo o método e também ilustra as cinco pontas da "Estrela de Galbraith".

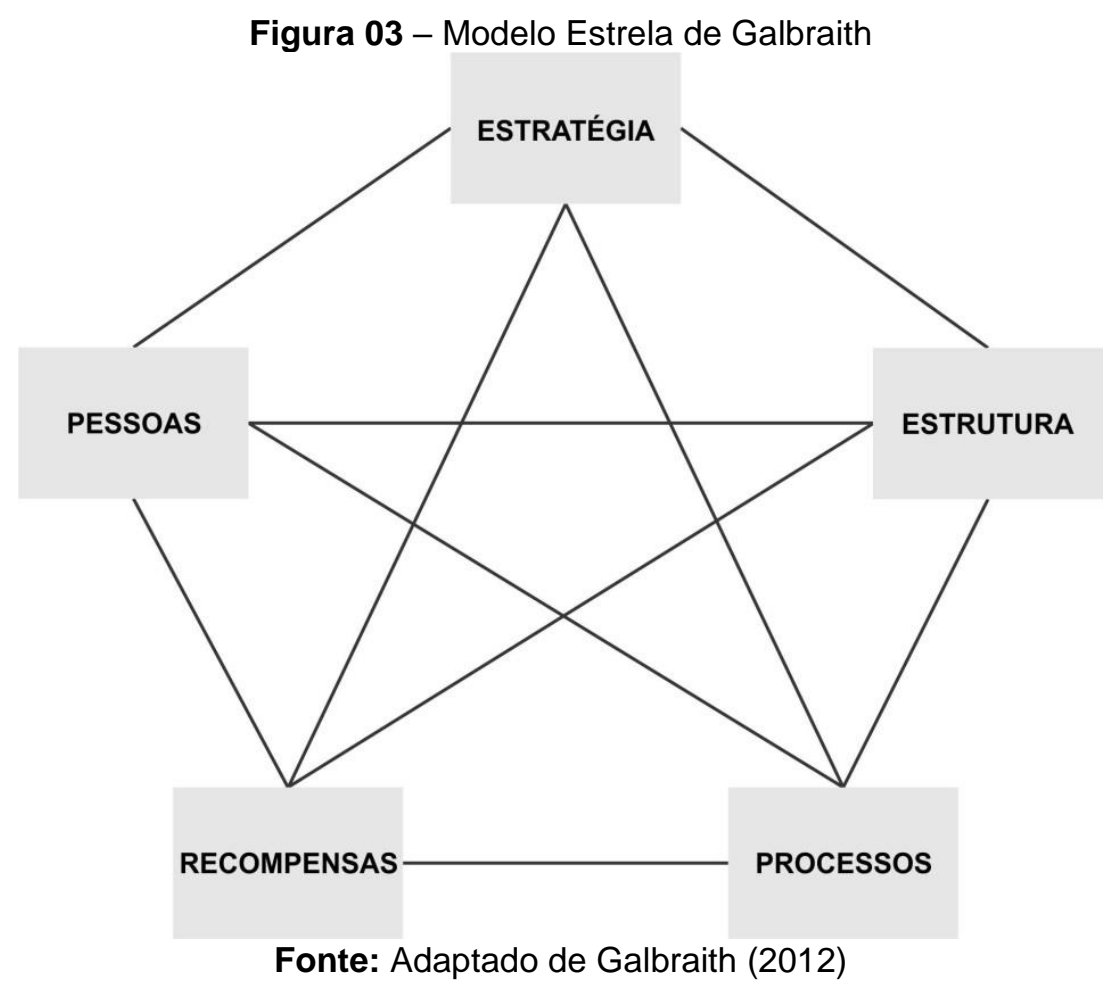

\subsection{Análise Comparativa}

Ao se efetuar uma análise comparativa entre os modelos citados, pode-se perceber a similaridade entre diversos pontos dos três modelos de gestão. Para facilitar a visualização prática da análise comparativa, a Tabela 01 apresenta as diferentes categorias analisadas e sua presença ou não frente aos três modelos os quais são identificados como "M1" para Estrela de Galbraith (GALBRAITH, 2012), "M2" para Seis Caixas (WEISBORD, 1976) e "M3" para McKinsey 7S (WATERMAN, PETERS, PHILLIPS, 1980). 
Tabela 01 - Análise comparativa entre modelos de gestão

\begin{tabular}{|c|c|c|c|c|}
\hline & CATEGORIAS & M1 & M2 & M3 \\
\hline \multirow{7}{*}{ 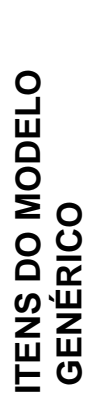 } & Estratégia & $x$ & & $x$ \\
\hline & Estrutura & $\mathbf{X}$ & $\mathbf{x}$ & $\mathbf{x}$ \\
\hline & Processos & $\mathbf{X}$ & & $\mathbf{x}$ \\
\hline & Recompensas & $\mathbf{X}$ & $\mathbf{x}$ & \\
\hline & Pessoas & $\mathbf{X}$ & $\mathbf{x}$ & $\mathbf{x}$ \\
\hline & Propósito & & $\mathbf{x}$ & \\
\hline & Mecanismos de auxílio & & $\mathbf{x}$ & \\
\hline \multirow{14}{*}{ 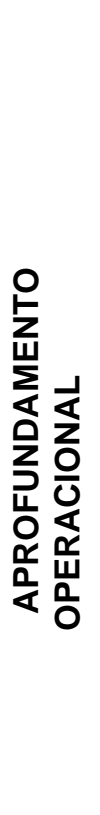 } & Liderança & & $\mathbf{x}$ & $\mathbf{x}$ \\
\hline & Habilidades & & & $x$ \\
\hline & Valores compartilhados & & & $\mathbf{x}$ \\
\hline & Mercado & & & \\
\hline & P\&D & & & \\
\hline & Fluxo de trabalho & $\mathbf{X}$ & & \\
\hline & Fluxo de informações & $\mathbf{X}$ & & \\
\hline & Gestão de conflitos & & $\mathbf{x}$ & \\
\hline & Setorização por processos & $\mathbf{x}$ & $\mathbf{x}$ & $\mathbf{x}$ \\
\hline & Ambiente & & $\mathbf{x}$ & \\
\hline & Controle e análise & & & \\
\hline & Cultura organizacional & & & \\
\hline & Hierarquização & $\mathbf{x}$ & $\mathbf{x}$ & $\mathbf{x}$ \\
\hline & Finanças & & & \\
\hline
\end{tabular}

Fonte: Autores (2020)

Todos estruturam suas representações em pilares principais, ou seja, em um agrupamento genérico das atribuições empresariais. Com isso, os três modelos apresentam contextos e grupos parecidos, também pelo fato de não se tratar de modelos específicos para determinados segmentos. Para a análise apresentada na tabela 01 , foi designado a este conjunto de itens o nome "itens dos modelos genéricos", pois são aqueles citados nos três modelos de gestão analisados e que demonstram caráter essencial na estruturação de um modelo de gestão.

Porém, também foi possível identificar a ausência de estruturas de controle de produtividade e ferramentas que busquem a manutenção da empresa com o passar do tempo como Pesquisa e Desenvolvimento (P\&D) e mercado, por exemplo. Os modelos analisados carecem de pontos mais específicos e de um aprofundamento operacional maior. Em se tratando de um modelo voltado para um nicho específico, a flexibilidade e o poder de personalização aumentam, o que contribui para a criação de 
itens relevantes na modernização e na adequação da empresa frente os desafios da globalização. Na análise a seguir, estes itens são agrupados e identificados como "aprofundamento operacional".

\section{METODOLOGIA}

A metodologia de uma pesquisa contempla o conjunto de etapas a serem percorridas no desenvolvimento da produção, iniciando na escolha do tema e finalizando na divulgação dos resultados, passando por outras etapas como planejamento da investigação, desenvolvimento metodológico, coleta e tabulação de dados, análise dos resultados e elaboração das conclusões (SILVA, MENEZES, 2005).

O método de pesquisa utilizado foi a Design Science Research (DSR) com o objetivo de propor um modelo de gestão voltado especificamente para micro e pequenas fábricas de móveis sob medida (marcenarias) buscando solucionar o problema de um setor majoritariamente guiado pelo empirismo.

Segundo Dresch, Lacerda e Antunes (2015) "a Design Science é a ciência que procura desenvolver e projetar soluções para melhorar sistemas existentes, resolver problemas ou, ainda, criar novos artefatos que contribuam para uma melhor atuação humana, seja na sociedade, seja nas organizações". Neste contexto, artefato pode ser considerado a organização de atributos e itens de um ambiente interno visando atingir objetivos de um ambiente externo (DRESCH, LACERDA, ANTUNES, 2015).

Este estudo busca elaborar um artefato que se apresente como um modelo de gestão para micro e pequenas empresas do setor de móveis sob medida. A construção deste modelo segue as dez primeiras etapas do método DSR, segundo Dresch, Lacerda e Antunes (2015). Tais etapas estão ilustradas abaixo na Figura 04, que pode ser considerada a estrutura para a elaboração de uma produção científica que tenha como base a DSR. 
Figura 04 - Etapas da Design Science Research

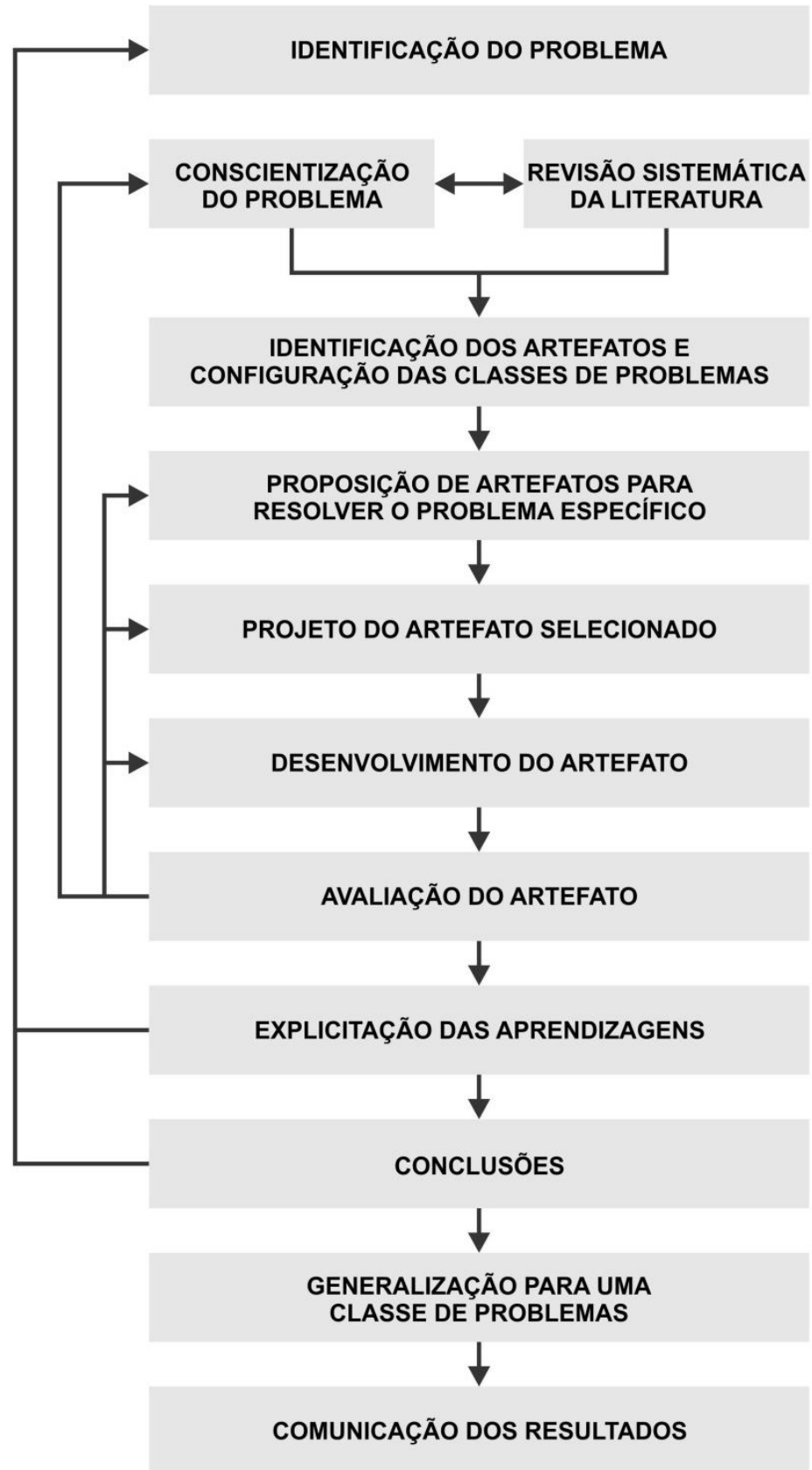

Fonte: adaptado de Dresch, Lacerda e Antunes (2015)

A Etapa 1 do método de trabalho foca na elaboração da questão problema e na visualização dos objetivos. Como seria um modelo de gestão desenvolvido especificamente para uma empresa de móveis sob medida? O interesse no tema e no problema proposto surge da identificação de um setor empresarial dominado pelo empirismo, onde as empresas são muitas vezes constituídas no âmbito familiar (LEÃO, 2010) e sua formalização não é tratada com rigor (GALINARI et al. 2013). 
A literatura descreve diversos modelos de gestão para empresas, mas não é possível encontrar nenhum focado em marcenarias, o que dificulta a implementação dos mesmos neste segmento. Ainda, grande parte dos gestores iniciam seus empreendimentos amparados unicamente em seus conhecimentos empíricos e, após o início das atividades, a implementação de um modelo genérico se torna uma tarefa de difícil execução.

Com isso, se propôs um modelo específico para micro e pequenas marcenarias, unindo pilares principais dos modelos de gestão pesquisados com processos e setores próprios deste tipo de empreendimento. Através deste modelo busca-se a contribuição para a manutenção da subsistência destas empresas no mercado atual e a capacitação da mesma para os desafios que se apresentam com o passar dos anos e a constante transformação dos perfis de consumo e níveis de exigência do mercado.

A segunda etapa trouxe a pesquisa por diversos modelos de gestão existentes na literatura e a busca pela compreensão mais aprofundada do setor moveleiro buscando identificar exatamente os pontos de melhoria e as questões a serem respondidas pelo artefato. Em complemento a real efetividade de um modelo de gestão específico foi analisada, as fases para o seu desenvolvimento foram estruturadas e a importância de um artefato que traga ao meio a compreensão de um tema tão vital para a estruturação e manutenção das empresas foi debatida.

Para a produção realizada apresentar dados e profundidade científica uma revisão da literatura foi necessária. Antes disso foi debatido e analisado quais seriam os pilares desta revisão. Nesta fase definiu-se os seguintes pilares:

Modelos de gestão: por ser o foco do artefato a ser desenvolvido. Foi necessário encontrar na literatura diferentes modelos já existentes e publicados para permitir um maior conhecimento na área em questão.

Modelos Seis Caixas, McKinsey 7s e Estrela de Galbraith: Após a revisão de diferentes modelos de gestão, foram selecionadas estas três produções para um aprofundamento do conhecimento e por consequência, uma análise comparativa entre elas. Estes modelos foram selecionados por conta de sua relevância científica e também por apresentarem diversos pontos de convergência e potencial de aplicação para o setor proposto. 
Foram encontrados três diferentes artefatos ligados ao tema da pesquisa e selecionados para aprofundamento teórico, junto disso, foram detectados potenciais problemas a serem solucionados pelo objetivo específico junto da formatação empresarial do setor. Quanto à classe do problema, o foco é a melhoria dos sistemas de gestão em micro e pequenas marcenarias do setor moveleiro.

Esta etapa se dá a partir do conteúdo pesquisado, do entendimento adquirido na busca do problema da pesquisa e da análise comparativa entre cada modelo, com o objetivo de identificar similaridades e divergências frente à questão problema. $A$ análise desenvolvida foi ilustrada em uma tabela presente no item 3. 2. 8 deste estudo.

Nesta etapa, usa-se os artefatos já analisados no item anterior. Os modelos de gestão Estrela de Galbraith (GALBRAITH, 2012), Seis Caixas (WEISBORD, 1976) e McKinsey 7S (WATERMAN, PETERS, PHILLIPS, 1980) são utilizados como base para o desenvolvimento de um novo artefato. Junto disso, foram inseridos tópicos de gestão contemporâneos voltados para auxiliar na manutenção da empresa frente à globalização e processos específicos das operações deste segmento.

O novo artefato sugere setores práticos e bem definidos. Entende-se que 0 fluxo dos processos de trabalho é algo a ser rigorosamente compreendido e respeitado, enquanto a distribuição de processos por colaboradores e a alocação dos mesmos nos setores fica a critério do empresário que deve levar em conta as virtudes e limitações do seu quadro de colaboradores para assim tomar as devidas decisões. Do mesmo modo, o artefato sugere principalmente o desenvolvimento de um olhar sistêmico do empresário sobre sua empresa, exigindo que consiga perceber os pilares fundamentais da estrutura empresarial e também a identificação do ambiente externo como centro/foco da operação.

Com o alinhamento das ideias propostas e a formação do artefato concluída, resulta a apresentação de um Modelo de Gestão para empresas do segmento de móveis sob medida. Visando solucionar o problema da dificuldade de estruturação e formalização das empresas deste segmento através de setores e processos.

Os modelos de gestão encontrados na revisão bibliográfica e a contextualização do setor moveleiro desenvolvida na mesma etapa foram de grande utilidade, cada um sob um aspecto. Os modelos trouxeram a identificação dos pilares principais que se fizeram presentes em todos os modelos e se mostraram fundamentais em cada um deles. E a análise setorial trouxe a identificação dos 
problemas enfrentados pelo empresariado, o desafio da continuidade e principalmente a dificuldade na formação e identificação de setores e processos internos e externos. Os cruzamentos das informações adquiridas sob estas duas frentes foram fundamentais para a estruturação do novo artefato.

A avaliação é a etapa onde é realizada a verificação do desempenho do artefato em questão em face ao objetivo para o qual foi projetado (LACERDA et al. 2013). A primeira versão do modelo foi avaliada por três profissionais especialistas com currículos apresentados na tabela 02 a seguir. $O$ intuito dessa avaliação é a coleta de considerações e avaliações para o aperfeiçoamento do artefato.

Tabela 02 - Especialistas participantes da avaliação

\begin{tabular}{ccc}
\hline PROFISSIONAL & CITAÇÃO & \multicolumn{1}{c}{ CURRÍCULO } \\
\hline ESPECIALISTA 1 & E1 & $\begin{array}{l}\text { Graduado em Engenharia de Segurança do Trabalho e } \\
\text { especializado na área. Atua como consultor empresarial em } \\
\text { Processos Industriais, Saúde e Segurança do Trabalho. E é } \\
\text { professor em disciplinas de administração, segurança e } \\
\text { sistemas de produção em diferentes instituições. }\end{array}$ \\
ESPECIALISTA 2 & E2 & $\begin{array}{l}\text { Doutor em Arquitetura e Urbanismo é Professor titular da } \\
\text { Universidade de Passo Fundo e coordenador do Curso } \\
\text { Superior em Tecnologia em Design de Produto e do } \\
\text { CETIMOV (Centro Vocacional e de Inovação Tecnológica da }\end{array}$ \\
ESPECIALISTA 3 & E3 & $\begin{array}{l}\text { Indústria Moveleira). } \\
\text { Bacharel em Design, e possui especialização em Design } \\
\text { Moveleiro com ênfase em Sistema, Produto e Serviço. Atuou } \\
\text { como consultor no Instituto Senai de Tecnologia Madeira e } \\
\text { Mobiliário e atualmente é Coordenador estadual de projetos } \\
\text { do setor moveleiro no Sebrae/RS. }\end{array}$ \\
\hline
\end{tabular}

Fonte: Os autores (2020)

A etapa de explicitação das aprendizagens é voltada para a apresentação dos resultados obtidos com o artefato desenvolvido, bem como os pontos fortes e fracos do processo de desenvolvimento e pesquisa. Com isso, o objetivo é facilitar o desenvolvimento de conhecimentos teóricos e práticos e propagar as intensões da pesquisa e do artefato em questão.

Na etapa 10, está a formalização geral do estudo realizado e é onde acontece a comunicação do artefato desenvolvido às comunidades acadêmicas e profissionais (LACERDA et al. 2013). Também podem ser apresentadas na etapa de conclusões todas as limitações encontradas pelos pesquisadores bem como as proposições para a sequência do trabalho. 


\section{RESULTADOS E DISCUSSÕES}

O artefato foi desenvolvido após a integração entre o conhecimento obtido por meio da interpretação da análise comparativa dos três modelos de gestão apresentados no referencial teórico, o aprofundamento do conhecimento do cenário e das características do setor moveleiro e o conhecimento experiencial do autor em cinco anos de atuação gerencial no setor.

\subsection{Modelo de Gestão Marcenaria 5A - Versão 1}

Esta versão inicial foi proposta pelo autor com base na aprendizagem gerada pela análise dos modelos. O modelo pode ser analisado na Figura 05 e foi nomeado Marcenaria 5A em função da disposição principal do artefato ser amparada em 5 áreas da empresa: Administrativo, Comercial, PCP, Produção e Entrega, Verghese (2007), aponta que a divisão por área é uma grande ferramenta para identificar forças, oportunidades e áreas problemáticas de uma organização.

A partir dessa macro classificação, o modelo apresenta o fluxo de trabalho e de informações que interligam cada uma das áreas, bem como o posicionamento do setor administrativo como figura de abrangência geral na empresa, estando envolto de todo o setor operacional que fica representado pelas áreas Comercial, PCP, Produção e Entrega.

O fluxo de informações é representado por uma linha tracejada com setas nas duas extremidades representando a necessidade de integração e diálogo entre cada um dos setores, uma vez que se trata de um processo produtivo personalizável e de um produto não escalável. Ainda, o fluxo de trabalho é representado por uma linha contínua com seta em apenas uma das pontas, o que denota claramente o caminho em que cada produto deve seguir.

Visando facilitar a compreensão das áreas (setores), cada uma foi representada de uma cor e dentro de cada uma delas estão os processos presentes em cada uma das etapas. Esta classificação (por setores e por processos) é o ponto de maior especificidade do artefato ao setor moveleiro, pois nestas classificações é onde se encontram cada um dos grandes grupos dos modelos genéricos e é o que 
facilita a compreensão e aplicação do método na indústria (GALBRAITH, 2012); (WEISBORD, 1976) e (WATERMAN, PETERS, PHILLIPS, 1980).

Por fim, também estão representados no artefato os ambientes internos e externos à empresa. $\mathrm{O}$ ambiente interno se dá pelo agrupamento dos cinco setores e o ambiente externo é onde se encontram os itens "mercado" e "cliente", os quais estão representados na parte central da ilustração do modelo proposto. Isso se dá com o propósito de representar que o mercado e os clientes são o "foco central" da empresa, ou seja, que a empresa deve "girar em torno destes itens", pois é deste ambiente que sai o "input" que dá início ao trabalho da empresa.

Cabe ressaltar, que o modelo proposto não apresenta em nenhuma parte a distribuição das pessoas dentro dos setores e processos, uma vez que, cada empresa deve fazer a gerência disso a partir da sua quantidade de funcionários e da gestão das competências. Sabe-se que empresas de micro e pequeno porte apresentam uma variedade muito grande em seu número de colaboradores e por isso, cada funcionário pode ocupar um ou mais processos e até mesmo setores conforme a necessidade de cada empresa. Porém, é importante ressaltar o cuidado necessário com a centralização das tarefas, fato presente em muitas empresas do segmento principalmente em se tratando do proprietário da empresa. 
Figura 05 - Modelo de gestão Marcenaria $5^{\underline{a}}-$ Versão 1
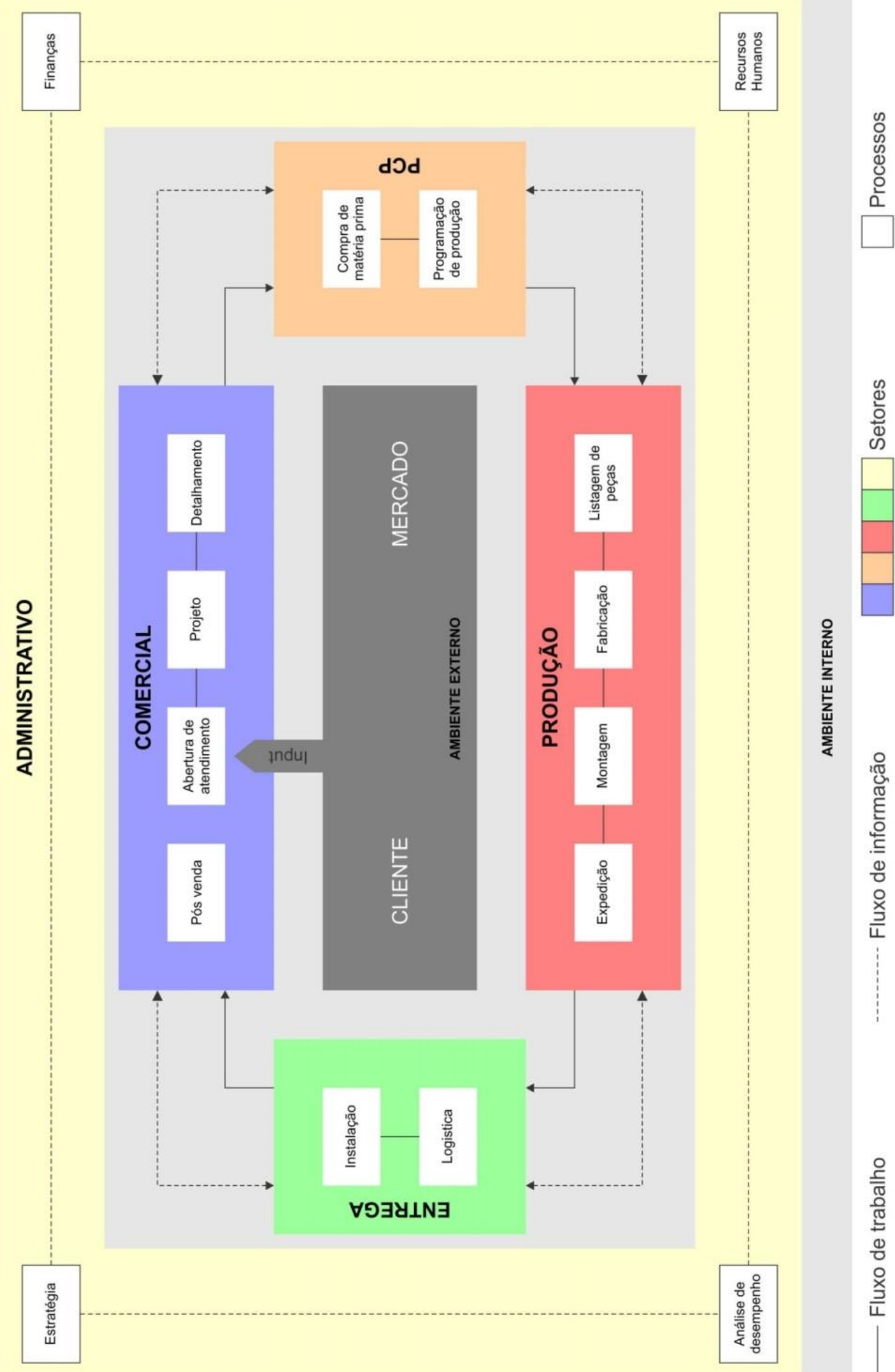

Fonte: Os autores (2020) 


\subsection{Avaliação dos Especialistas}

A primeira versão do modelo de gestão foi apresentada para os três especialistas, Quadro 01, com o intuito de identificar eventuais pontos de melhorias e validar as ideias propostas. Cada profissional fez as suas contribuições que posteriormente foram analisadas e compiladas em uma segunda versão do artefato.

Abaixo, seguem algumas contribuições do profissional E1:

- O agrupamento dos setores e dos processos em caixas remete a ideia de grupos de pessoas. Mesmo estando bem diagramado e tendo uma boa representação de fluxos, é importante destacar visual ou textualmente aonde se encaixa cada colaborador neste modelo.

- Nos dias de hoje é de extrema importância que as empresas tenham seu foco na inovação de produto, é recomendável que este conceito esteja presente no modelo.

- O item estratégia é o norteador de todos os processos dentro da empresa, é importante que se mantenha presente e, se possível, em destaque.

- A nomenclatura "montagem" não está adequada no setor de produção, pois o que é feito de fato é apenas uma montagem inicial do produto. A montagem completa neste estágio do fluxo de trabalho deflagraria um retrabalho no processo produtivo.

- Buscar outra palavra para representar o processo "fabricação" é aconselhado visto que todo o setor de produção trata da fabricação do móvel. Porém, seria necessária uma pesquisa aprofundada para identificar a palavra mais apropriada.

- O processo "listagem de peças" deve estar presente no setor de PCP uma vez que faz parte de composição técnica do móvel antecedendo o processo de produção.

- Questiona-se o fluxo de informações no sentido oposto ao fluxo de trabalho, principalmente quando do setor de produção para o PCP.

- É importante uma representação mais clara do ponto exato de início do fluxo de trabalho, sendo necessária uma marcação entre os processos de pós venda e de abertura de atendimento. 
- O levantamento dos custos do produto e a formação do preço de venda são pontos fundamentais para a manutenção da empresa e devem aparecer no modelo.

- A ligação entre um processo e outro deve ser representada por uma linha com uma seta na extremidade bem como a ligação entre um setor e outro.

As contribuições do profissional E2 foram direcionadas, principalmente, ao tema do artefato e não apenas as melhorias do modelo. São elas:

- O tema em questão apresenta uma grande representatividade no cenário atual, é debatido entre profissionais atuantes no segmento e foco de consultores empresariais.

- A ilustração apresenta uma boa diagramação e se destaca pela correta representação dos fluxos e dos ciclos. A representação se mostra intuitiva e isso é fundamental para a aplicação no setor, uma vez que, quanto mais prática e objetiva for, melhor para a interpretação do empresário.

- O centro do modelo representar o ambiente externo se mostra contraditório quando visto de forma superficial, mas compreensivo e adequado quando analisado por completo. Uma vez que, os pilares ali presentes (mercado e cliente) devem ser vistos como foco principal da empresa.

- É recomendável estabelecer uma relação direta entre pós venda, cliente e o input de início do processo comercial. Essa relação pode ser criada por meio da troca de posição da seta "input", da implantação do fluxo de informação entre os três itens ou de uma alteração gráfica do ambiente externo. O importante é que o artefato não represente uma empresa de ações exclusivamente reativas frente ao mercado e seus clientes.

- Propor um modelo de gestão é apenas uma tarefa inicial frente à abrangência e a importância do tema no âmbito setorial. Para explorar todo o potencial do artefato, é importante que seja elaborada uma metodologia de aplicação. Dado que mais intuitivo que se mostre a representação, a implementação do mesmo nas indústrias é um grande desafio aos empreendedores.

Com seus conhecimentos e experiências, o profissional E3 contribuiu com considerações para o modelo. Dentre elas, destacam-se: 
- O processo de "Listagem de Peças" não deve ser incluído no setor de produção e sim no setor de PCP ou até mesmo no setor comercial, dependendo do nível de informatização e automação presente na empresa em questão.

- A representação por meio de caixas dificulta a identificação de um processo cíclico, porém, a diagramação do artefato está compensando este fato e não tornando este um problema gráfico.

- O setor de PCP é responsável "apenas" pela gestão do estoque e pela logística necessária na compra da matéria prima e não pela definição da matéria prima, isso é um processo integrado ao "detalhamento comercial".

- O input ser representado como uma seta do ambiente externo em direção ao ambiente interno representa que a empresa atua apenas de forma reativa ao mercado e não de forma prospectiva. Essa alteração é indicada para incentivar a visão dos empreendedores em prol de posicionamento digital, parcerias com arquitetos, designers e fornecedores e principalmente a busca pelo cliente.

- O processo de "Montagem" deve ser identificado como "Pré montagem", pois a montagem completa do móvel não é necessária nesta etapa.

- O processo "Análise de desempenho" deve estar inserido em cada um dos setores e, principalmente, dentro do planejamento da empresa. Indica-lo como processo presente apenas no administrativo é um equívoco. O setor administrativo deve ser composto pelos itens: finanças, recursos humanos, mercado, processos e planejamento.

- Não está presente nesta versão nenhum ponto referente à orçamentação do produto o que deve ser incluído no setor comercial entre projeto e detalhamento dada a importância de tal processo.

- As nomenclaturas do setor "entrega" não estão adequadas, pois não representam intuitivamente cada processo.

\subsection{MODELO DE GESTÃO MARCENARIA 5A - VERSÃO 2}

Após a avaliação dos três especialistas sobre a versão inicial foi feita uma análise de suas ponderações sobre o tema, bem como uma avaliação de quais 
deveriam ser implementadas ao artefato. Durante este processo e na busca pelo aperfeiçoamento técnico e metodológico do modelo, novos insights surgiram e complementaram a criação da versão. Abaixo, seguem as principais alterações:

- Incorporação do item "análise de desempenho" ao item "estratégia" e definição do item "Processos" como pilar do setor administrativo.

- Identificação do ambiente interno também como estrutura e do ambiente externo também como mercado. Neste último, foi feita a ampliação dos itens nele presentes.

- Alterações de nomenclaturas como: de entrega para execução, de montagem para pré montagem, de logística para transporte, de instalação para montagem e de "input" para "start", marcando o início de um novo fluxo de trabalho.

- Inserção de três novos processos: orçamento e venda no setor comercial e controle de estoque no PCP.

- Alteração do processo "listagem de peças" do setor de produção para o PCP.

- Novas linhas de fluxo de informação identificadas como: indicação (ligando o final com o início de um novo processo / ação reativa), marketing (ligando o "start" com o mercado / ação propositiva) e P\&D (Ligando o processo criativo ao mercado / foco em inovação). A Figura 06 mostra a segunda versão do modelo de gestão, já apresentando todas as mudanças citadas anteriormente. 
Figura 06 - Modelo de gestão Marcenaria 5A - Versão 2

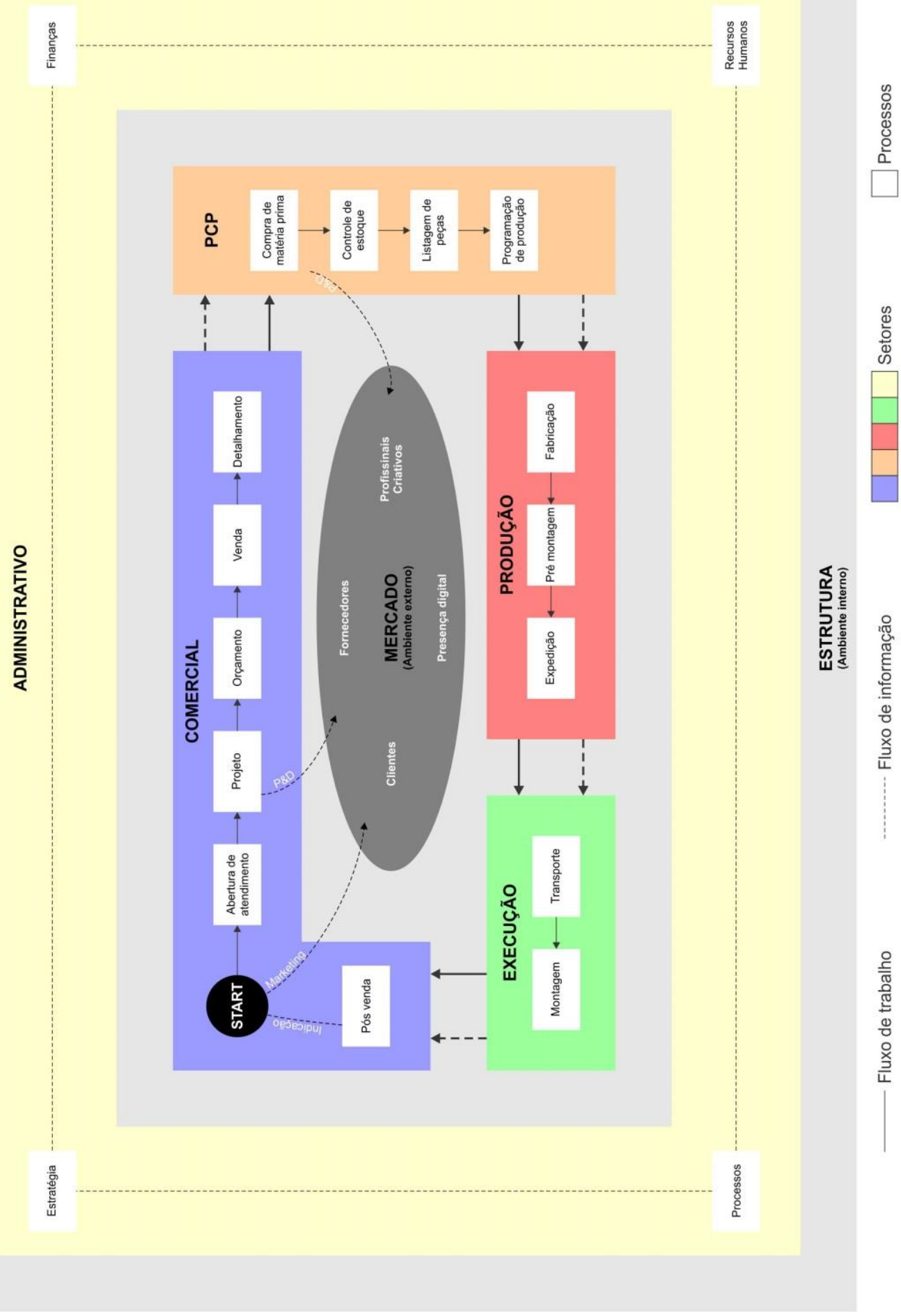

Fonte: Os autores (2020)

A partir das alterações definidas e do desenvolvimento da versão 2 do modelo Marcenaria 5A, segue abaixo a descrição das 5 áreas estruturadas pelo modelo. Cada 
uma delas com sua devida função no fluxo de trabalho e com seus respectivos processos em destaque.

\subsubsection{Administrativo}

O setor administrativo é o responsável pelo processo gerencial da empresa. As pessoas nele presentes são as responsáveis pela gestão e tomadas de decisões estratégicas. Em não se tratando de um setor que tem intervenção operacional no produto fim, ele se encontra fora do fluxo de trabalho. Porém, este setor está representado no entorno de todos os demais setores por se tratar do grande responsável pela manutenção da operação da empresa, apresentando influência em cada um dos setores e também processos existentes. No artefato, os quatro processos da área administrativa são: estratégia, finanças, recursos humanos e processos.

A Estratégia, como ressaltado pelo profissional E1 é considerada a norteadora de todas as ações da empresa. Este item tem sua importância ainda mais destacada uma vez que se mostra presente nos três modelos de gestão apresentados pelo referencial teórico, definido como estratégia em Estrela de Galbraith (GALBRAITH, 2012) e McKinsey 7s (WATERMAN, PETERS, PHILLIPS, 1980) e como propósitos em Seis Caixas (WEISBORD, 1976).

Finanças é o pilar que busca a saúde financeira da empresa, o que é um grande desafio para as Micro e Pequenas empresas do cenário nacional. Também é um pilar relevante visto a citação referente a custos e preço de venda dos profissionais E1 e E2.

Recursos Humanos é onde estão alocadas as pessoas que compõem a empresa e todas as suas demais relações. Este processo é essencial para o progresso da empresa e não por menos, também é citado nos modelos Estrela de Galbraith (GALBRAITH, 2012) e McKinsey 7S (WATERMAN, PETERS, PHILLIPS, 1980). Nesse processo é onde ficam contemplados também outros itens dos modelos estudados como: Habilidades (WATERMAN, PETERS, PHILLIPS, 1980) uma vez que nos recursos humanos são identificados os potenciais de cada colaborador para melhor alocá-los na estrutura. Recompensas (GALBRAITH, 2012); (WEISBORD, 1976), pois é onde se estruturam os mecanismos de comissões, bônus e benefícios. 
Relacionamentos (WEISBORD, 1976) buscando a manutenção de um agradável ambiente de trabalho. E Estilos (WATERMAN, PETERS, PHILLIPS, 1980) que é a determinação da forma de diálogo e tipo de liderança usada interna e externamente.

Por fim, o pilar Processos é o que representa a relevância do mapeamento e da planificação das etapas de trabalho presentes na empresa. Isso se faz necessário para melhorar a compreensão da complexidade da empresa, para a identificação da origem dos problemas e para a posição de cada pessoa na estrutura bem como suas devidas atribuições. Este item foi selecionado a partir da identificação dele nos modelos Estrela de Galbraith (GALBRAITH, 2012) e Seis Caixas (WEISBORD, 1976) e pela indicação do profissional E3 que apontou e justificou a importância sob estes e outros aspectos.

\subsubsection{Comercial}

É no setor comercial que todo o trabalho operacional da empresa começa (Start) e termina (Pós venda). Ele é o responsável pelo processo criativo da empresa. Ele é acionado pelo recebimento do input externo e deve transformar esse input em faturamento efetivo para a empresa.

Mercadologicamente, o setor comercial é responsável por transformar os desejos e necessidades do cliente em um produto a ser vendido, fabricado e executado conforme as capacidades e limitações da empresa. Os profissionais deste setor são quem deve: receber o cliente (abertura de atendimento), criar (Projeto), definir o preço (Orçamento), comercializar (Venda) e detalhar minuciosamente o produto da empresa (Detalhamento).

Operacionalmente, este é o setor responsável por definir o produto da empresa fazendo uso de sua ligação com o mercado através dos recursos de Pesquisa e Desenvolvimento (P\&D). Visando atender as oportunidades de mercado e ofertar inovações em serviços e produtos, o setor comercial é o responsável pelo processo criativo da empresa. Ao fim do seu fluxo de trabalho, é do detalhamento que saem as diretrizes de produção, listas de materiais e informações necessárias para o PCP dar sequência ao trabalho. 
Destacam-se aqui as contribuições dos especialistas com o intuito de direcionar a empresa ao foco em inovação e a responsabilidade financeira por meio do levantamento de custos e orçamentação do pedido.

A presença do comercial no encerramento do fluxo de trabalho se dá por meio do pós-venda, visando a manutenção do relacionamento com o cliente através de indicações e também procurando compreender as percepções do mesmo sobre a experiência de consumo com a empresa. Desta etapa também surgem as ações de publicidade a serem desenvolvidas e utilizadas pela empresa para conectar-se com o mercado tanto sob o aspecto reativo (indicações) como propositivo (marketing).

\subsubsection{PCP}

Planejamento e Controle da Produção (PCP) é o que representa o nome deste setor e também concisamente define sua função no fluxo de trabalho. É nesta etapa que se solidifica o processo técnico do item comercializado, transformando as informações e detalhamentos comerciais em peças (Listagem de peças) a serem manufaturadas e transformadas em produto final. Este é o setor responsável pela aquisição (Compra de Matéria Prima) e gestão dos recursos necessários (Controle de Estoque), organização das prioridades e ordem dos trabalhos a serem executados (Programação de Produção).

É atribuída a essa área a pesquisa e prototipagem de novos recursos a serem ofertados aos clientes como sistemas de fixação, ferragens e acabamentos. Também fica a cargo do PCP a busca por recursos em prol da produtividade e do progresso do processo produtivo como: mecanismos de controle e gestão da operação, novas máquinas ferramentas e estruturas (P\&D).

\subsubsection{Produção}

É no setor de produção que a manufatura e a operacionalização se iniciam dando início ao processo produtivo. Este é o setor responsável por transformar as informações recebidas pelo setor comercial e as matérias primas recebidas pelo PCP em produto. O processo se inicia com o corte, acabamento e elaboração das diferentes peças necessárias (Fabricação), passa por um estágio de montagem 
intermediária (Pré Montagem) e finaliza na conferência do produto (Expedição) em face ao desenvolvido pelo comercial. Ao fim deste processo, o produto é disponibilizado ao setor de execução para que seja transportado.

Nessa proposição, faz-se necessária a ressalva destacada pelos profissionais E1 e E3 que confere ao processo de montagem no setor de produção a instância de intermediário ratificando a possibilidade de um retrabalho que surgiria com dois processos completos de montagem. Dentro da produção, este processo tem como foco o teste das ferragens e matérias primas em geral que eventualmente podem apresentar defeitos, a diminuição do tempo de trabalho fora da empresa e também garantir a correta fabricação do produto e consequentemente a redução de problemas gerados por peças com tamanhos inadequados.

\subsubsection{Execução}

Tendo em vista que a marcenaria trabalha com a criação e produção de itens individuais e únicos, cada produto é desenvolvido exclusivamente para seu local e cliente. Com isso, o setor de execução é fundamental para o desenvolvimento da atividade operacional.

Este setor é responsável pela finalização do processo produtivo, estabelecido pelo translado do produto até o local para o qual foi desenvolvido (Transporte) e a instalação do mesmo (Montagem). Aqui se somam serviços que a empresa pode ofertar como diferencial competitivo ao mercado como: instalações elétricas e hidráulicas inerentes aos produtos comercializados e acréscimo de iluminações, estofamentos, adesivos, espelhos, vidros, etc.

Neste setor é importante destacar o comprometimento com a manutenção do cliente, uma vez que, praticamente todo o trabalho é feito em um ambiente externo a empresa, sendo necessários cuidados muito maiores com o espaço físico e resíduos resultantes da operação. No que tange as definições aqui presentes, destaca-se a influência do profissional E3 na definição das nomenclaturas deste setor, tornando-as mais claras e intuitivas. 


\subsubsection{Ambiente Interno e Externo}

As determinações de ambiente interno e externo não são consideradas demarcação de setores nem processos propriamente ditos e sim a classificação obtida pela presença dos itens no âmbito interno ou externo em face à empresa.

O ambiente externo (Mercado) é assim chamado por representar todos os players, oportunidades e fatores gerais que não fazem parte da composição interna da empresa. Em outras palavras, que não estão sob gerência do administrativo. Tais itens podem e devem ser identificados, observados, analisados e estudados pelos gestores, porém não há como agir diretamente para a definição e alteração de cada um dos pilares presentes. A presença desta classificação foi trazida do modelo de gestão Seis Caixas que representa o ambiente externo por fora do ciclo de operações (WEISBORD, 1976). Porém, no artefato proposto a diagramação utilizada foi inversa a do modelo apresentado no referencial teórico, uma vez que se busca introduzir a ideia de que o centro da representação é o foco da empresa, pois ali se encontram os clientes e as oportunidades de faturamento (Ponto positivamente destacado pelos profissionais E1 e E2).

Aparecem no ambiente externo os clientes que são o foco principal da empresa, os fornecedores que são parcerias fundamentais para o ritmo da empresa, profissionais criativos que podem ser prospectados e atendidos com o objetivo de atrair faturamento para a empresa e presença digital que se mostra cada vez mais importante para as empresas a partir do advento da internet.

Já o ambiente interno (Estrutura), é resultante do agrupamento das cinco áreas da empresa, tendo consolidada sua identificação e importância ao estar presente também nos modelos Estrela de Galbraith (GALBRAITH, 2012) e McKinsey 7s (WATERMAN, PETERS, PHILLIPS, 1980). Este item é a união entre os processos gerencial, criativo, técnico e produtivo. Todos estes, podendo receber interferência e direcionamento da gestão da empresa e que tem na estrutura uma identificação consolidada e importante como presente nos modelos Estrela de Galbraith (GALBRAITH, 2012) e McKinsey 7s (WATERMAN, PETERS, PHILLIPS, 1980).

No que tange a alocação de funcionários, é de extrema importância ressaltar que o artefato proposto não cita na representação a distribuição de pessoas entre os processos. Uma vez que, este ponto é de responsabilidade da gerência na alocação 
conforme as habilidades e o número de colaboradores existentes. É natural que em micro e pequenas empresas uma mesma pessoa esteja presente e até mesmo seja responsável por uma ou mais áreas e processos.

\section{CONCLUSÕES}

Este trabalho teve como objetivo propor um modelo de gestão para marcenarias de micro e pequeno porte com o intuito de que os empresários possam conhecer, estruturar e qualificar seus empreendimentos. Com isso, o objetivo foi alcançado através da representação gráfica elaborada resultante da união dos conhecimentos obtidos anteriormente por meio das experiências do autor, dos conhecimentos acadêmicos e teóricos adquiridos através das pesquisas e análises de diferentes modelos existentes e da capacitada avaliação de cada um dos especialistas que se dispuseram a contribuir. O modelo desenvolvido foca nas seguintes áreas: Administrativo, Comercial, Programação e Controle de Produção, Produção e Execução.

A limitação deste estudo esta relacionada à aplicação do artefato dentro de empresas existentes. Devido aos prazos impostos para a realização e a carga de pesquisas e leituras feitas para a proposição, não foi possível aplicar o modelo. Por conta disso, o aperfeiçoamento do método proposto ficou restrito aos conhecimentos, análises e compreensões do pesquisador e as avaliações e contribuições dos especialistas convidados.

Espera-se poder colaborar com a manutenção das micro e pequenas marcenarias a partir do modelo proposto, permitindo e instigando um olhar inovador dos empresários junto aos ambientes interno e externos à empresa.

Para futuras pesquisas e consequentes produções, surge a oportunidade de integração do artefato com o mercado através da apresentação da ilustração para empresários buscando a consequente aplicação nos empreendimentos. Como destacado pelos profissionais E2 e E3 durante sua contribuição ao estudo, é relevante para a sequência o desenvolvimento de uma metodologia de aplicação do modelo proposto, visto que o tema é de relevância e necessidade às micro e pequenas empresas do setor. Tal elaboração pode, possivelmente, iniciar pela identificação da presença ou não de um modelo de gestão dentro de cada empresa e posteriormente 
a planificação dos processos e setores para que possam fazer um cruzamento com o proposto no Modelo Marcenaria 5A.

\section{REFERÊNCIAS}

BRASIL. Lei Complementar (LC) no 123, de 14 de dezembro de 2006, atualizada pela LC no 155, de 27 de outubro de 2016. Disponível em:

https://www2.camara.leg.br/legin/fed/leicom/2016/leicomplementar-155-27-outubro-2016-

783850-publicacaooriginal-151329-pl.html

BURKE, W. Warner; LITWIN, George H. . A causal model of organization performance and change. Journal of Management. Thousand Oaks (EUA), v. 18, n. 3, 1992, p. 523-545. Disponível em:

http://www.exeter.ac.uk/media/universityofexeter/humanresources/documents/learningdevelo pment/understanding drivers for change.pdf.

CHEAL, Joe. The logical level 7s matrix. 2008. Disponível em: http://gwiznlp.com/Logical\%20Levels\%207S\%20Matrix.pdf.

DRESCH, Aline; LACERDA, Daniel Pacheco; ANTUNES, José Antonio Valle. Design science research: método de pesquisa para avanço da ciência e tecnologia. Porto Alegre: Bookman, 2015. xxii, 181 p.: il.; 25cm

DUTRA, Ademar. Metodologias para avaliar o desempenho organizacional: revisão e proposta de uma abordagem multicritério. 2005. Disponível em: https://dialnet.unirioja.es/descarga/articulo/2898023.pdf

FEREIRA et al. Relatório de acompanhamento setorial: indústria moveleira. Disponível em: https://www3.eco.unicamp.br/neit/images/stories/arquivos/RelatorioABDI/moveleira voll junho2008.pdf

FUJITA et al. Breve panorama da indústria moveleira: mercado, design e meio ambiente. 2015. Disponível em: http://www.utfpr.edu.br/curitiba/estruturauniversitaria/diretorias/dirppg/grupos/tema/12breve panorama indu moveleira.pdf>

GALBRAITH, Jay R. Star Model. Central Valley (EUA), 29 fevereiro 2012. Disponível em: http://www.cvapinc.org/files/StarModel.pdf.

GALINARI et al. A competitividade da indústria de móveis do Brasil: situação atual e perspectivas. 2013. Disponível em: https://web.bndes.net/bib/jspui/handle/1408/1516

GORINI, Ana Paula Fontenelle. Panorama do setor moveleiro, com ênfase na competitividade externa a partir do desenvolvimento da cadeia industrial de produtos sólidos de madeira, 1998. Disponível:

http://arquivos.sindicatodaindustria.com.br/app/cni sindicatos/2011/01/10/123/20150819100 $\underline{413531341 \text { e.pdf }}$

GUIMARÃES, Andréa Bastos da S; CARVALHO, Kátia C. Medeiros de; PAIXÃO, Luiz Andrés Ribeiro. Micro, pequenas e médias empresas: conceitos e estatísticas. Disponível em: http://repositorio.ipea.gov.br/bitstream/11058/8274/1/Radar n55 micro pequenas.pdf 
HAMID et al.. The analysis of organizational diagnosis on based six box model in universities. 2011. Disponível em: https://files.eric.ed.gov/fulltext/EJ1080932.pdf

KILMANN, Ralph H. Beyond the quick fix: managing five tracks to organizational success. San Francisco: Jossey-Bass. https://doi.org/10.1177/017084068600700116

LACERDA at al. Design Science Research: método de pesquisa para a engenharia de produção. Gest. Prod., São Carlos, v. 20, n. 4, p. 741-761, 2013 Disponível em: http://www.scielo.br/scielo.php?script=sci arttext\&pid=S0104530X2013000400001\&lng=en\&nrm=iso.

LEÃO, M. S., NAVEIRO, R. M. Móveis: indústria de móveis mostra competitividade da madeira brasileira. 2010. Disponível:

http://www.cgimoveis.com.br/economia/documento.2010-06$\underline{08.6642478173 / \text { at download/arquivo }}$

MCMILLAN, Elizabeth. Considering organization structure and design from a complexity paradigm perspective. In: FRIZZELLE, G.; RICHARDS, H. Tackling industrial complexity: the ideas that make a difference. Cambridge, Inglaterra: Institute of Manufacturing, University of Cambridge, 2002, p. 123-136. Disponível em: http://oro.open.ac.uk/2732/.

OCDE - Organização para Cooperação e Desenvolvimento Econômico. Manual de Oslo: diretrizes para coleta e interpretação de dados sobre inovação. Disponível em: http://www.finep.gov.br/images/apoio-e-financiamento/manualoslo.pdf

RAVANFAR, MM. Analyzing organizational structure based on 7s model of mckinsey. Global Journal of Management And Business Research, oct. 2015. Disponível em: https://journalofbusiness.org/index.php/GJMBR/article/view/1792.

SANTOS et al. Design na indústria brasileira de móveis. 1999. São Paulo: Sebrae/Finep/Abimóvel/Fecamp/Unicamp-IE-Neit.

SILVA, MENEZES. Metodologia da pesquisa e elaboração de dissertação. 4. ed. rev. atual. - Florianópolis: UFSC. Disponível em:

https://projetos.inf.ufsc.br/arquivos/Metodologia de pesquisa e elaboracao de teses e di ssertacoes 4ed.pdf

VERGHESE, Annie. OD interventions for sustainable excellence in higher education. 2007. Disponível em:

http://citeseerx.ist.psu.edu/viewdoc/download?doi=10.1.1.493.4972\&rep=rep1\&type=pdf

WATERMAN Jr, Robert H.; PETERS, Thomas J.; PHILLIPS, Julien R. Structure is not Organization. Business Horizions, v. 22. n. 3, p. 14-26. 1980. https://doi.org/10.1016/0007$\underline{6813(80) 90027-0}$

WEISBORD, Marvin. Organizational diagnosis, six places to look for trouble with or without a theory. The Journal of group and organizational management, v. 1, n. 4, p. 430-447. 1976. http://dx.doi.org/10.1177/0021886398342003

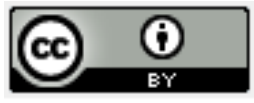

Artigo recebido em: 11/06/2020 e aceito para publicação em: 01/07/2021

DOI: https://doi.org/10.14488/1676-1901.v21i3.4069 